\title{
ANATOMIA DA MADEIRA DE MYRCIANTHES PUNGENS (O. BERG) D. LEGRAND (MYRTACEAE) ${ }^{1}$
}

\author{
SIDINEI RODRIGUES DOS SANTOS² JOSÉ NEWTON CARDOSO MARCHIORI ${ }^{3}$
}

\section{RESUMO}

São descritos e ilustrados os caracteres microscópicos da madeira de Myrcianthes pungens (O. Berg) D. Legrand, a partir de amostras coletadas no Rio Grande do Sul. A estrutura anatômica reúne características típicas da família Myrtaceae, tais como: porosidade difusa; poros muito numerosos e solitários; elementos vasculares de comprimento médio; placas de perfuração simples; pontoações intervasculares alternas; espessamentos espiralados ausentes; raios heterogêneos, estreitos; e fibras de comprimento médio, com pontoações areoladas. Sob o ponto de vista taxonômico, destaca-se a presença de parênquima axial em faixas tangenciais, por sua ocorrência mais restrita na família.

Palavras-chave: Myrcianthes pungens, anatomia da madeira, Myrtaceae.

\section{ABSTRACT \\ [Wood anatomy of Myrcianthes pungens (O. Berg) D. Legrand (Myrtaceae)].}

The wood anatomy of Myrcianthes pungens (O. Berg) D. Legrand is described and illustrated, based on samples from Rio Grande do Sul state, Brazil. Several characteristics, that are common in the Myrtaceae were observed: diffuse porous wood; very numerous and solitary pores; medium size vessel elements; alternate intervessel pits; spiral thickenings absent; narrow and heterogeneous rays; and medium size fibres, with bordered pits. From the taxonomic point of view, the tangential band axial parenchyma proved special importance, due to the scarceness in its botanical family.

Key words: Myrcianthes pungens, wood anatomy, Myrtaceae.

\section{INTRODUÇÃO}

Myrcianthes pungens (O. Berg) D. Legrand, o popular guabiju, é uma Myrtaceae Myrtoideae bastante conhecida no Rio Grande do Sul, tanto por sua vasta área de ocorrência, como pelo sabor dos frutos. Espécie mais popular, das três de seu gênero ocorrentes no Estado (Sobral, 2003), Myrcianthes pungens é facilmente reconhecida pelos frutos aveludados, amarelo-

1 Recebido para publicação em 10/08/2009 e aceito para publicação em 15/10/2009.

2 Biólogo, bolsista do CNPq - Brasil, doutorando do Programa de Pós-Graduação em Engenharia Florestal, Departamento de Ciências Florestais, Universidade Federal de Santa Maria, CEP 97105-900, Santa Maria, RS, Brasil.sthurt.bio@gmail.com

${ }^{3}$ Engenheiro Florestal, Dr., bolsista de Produtividade em Pesquisa (CNPq - Brasil), Professor Titular do Departamento de Ciências Florestais, Universidade Federal de Santa Maria, Santa Maria, RS, Brasil. enegrecidos e de cálice persistente, bem como pelas folhas terminadas em espinho.

Árvore de porte médio a grande (até $20 \mathrm{~m}$ de altura e $60 \mathrm{~cm}$ de D.A.P.), produz madeira comercialmente importante, dura, elástica, pesada $\left(0,98 \mathrm{~g} / \mathrm{cm}^{3}\right)$ e resistente (Silva, 1967), indicada para construção civil, obras de torno e marcenaria de luxo (Lorenzi, 1992).

De ampla distribuição geográfica, o guabiju ocorre naturalmente do Uruguai ao estado de São Paulo, incluindo parte da Bolívia, Paraguai, e Argentina (Sobral, 2003).

Integrante de uma série de publicações anatômicas, o presente estudo tem o objetivo de contribuir para o conhecimento estrutural das Mirtáceas nativas no Rio Grande do Sul.

\section{REVISÃO DE LITERATURA}

A despeito de sua importância regional, não constam referências anatômicas sobre as madei- 
ras de Myrcianthes, nas obras clássicas de Record \& Hess (1949) e Metcalfe \& Chalk (1972). Para Myrcianthes gigantea, todavia, Marchiori et al. (2008) referem, entre outros aspectos: poros solitários $(27 \mu \mathrm{m})$; elementos vasculares de comprimento médio $(542 \mu \mathrm{m})$; placas de perfuração simples; espessamentos espiralados ausentes; parênquima apotraqueal difuso-em-agregados, em séries com 5 - 8 células; raios heterogêneos com 1 - 3 células de largura e 100 - $312 \mu \mathrm{m}$ de altura; fibras com pontoações areoladas; e ausência de traqueídeos e cristais.

Para a espécie em estudo, Richter \& Dallwitz (2009) relacionam: porosidade difusa; poros exclusivamente solitários $(24 \mu \mathrm{m})$ e sem conteúdos; elementos vasculares com placas de perfuração simples; pontoações intervasculares alternas, não guarnecidas; espessamentos espiralados ausentes; pontoações raiovasculares semelhantes às intervasculares; parênquima axial em faixas não marginais, com $2-6$ células de largura, por vezes descontínuas, além de apotraqueal difuso e difuso-em-agregados; séries parenquimáticas com 3 - 5 células de altura; raios heterocelulares com $1-3$ células de largura e 500 a $1000 \mu \mathrm{m}$ de altura; presença de células com paredes disjuntas; fibras com pontoações areoladas, de paredes mediamente espessas e não septadas; e presença de traqueídeos.

\section{MATERIAL E MÉTODOS}

O material, procedente de Santa Maria (Rio Grande do Sul), consiste de duas amostras de madeira e respectivos materiais botânicos, incorporados à Xiloteca e Herbário do Departamento de Ciências Florestais da Universidade Federal de Santa Maria (HDCF), sob os números 2509 e 6015.

Do material lenhoso foram extraídos três corpos de prova $(3 \times 3 \times 3 \mathrm{~cm})$ da parte mais externa do lenho, próxima ao câmbio, orientados para obtenção de cortes nos planos transversal, longitudinal radial e longitudinal tangencial. Um outro bloquinho foi também retirado, com vistas à maceração.

No preparo de lâminas histológicas, seguiuse a técnica padrão no Laboratório de Anatomia da Madeira da Universidade Federal do Paraná: as amostras de madeira foram amolecidas por fervura em água e seccionadas em micrótomo de deslizamento, regulado para a obtenção de cortes com espessura nominal de $20 \mu \mathrm{m}$. Os cortes foram tingidos com acridinavermelha, crisoidina e azul-de-astra (Dujardin, 1964), desidratados em série alcoólica-ascendente $(30 \%, 50 \%, 70 \%, 95 \%$ e duas vezes em álcool absoluto), diafanizados em xilol e montados em lâminas permanentes, com Entellan.

Para as lâminas de macerado, adotou-se o método de Jeffrey (Burger \& Richter, 1991), coloração da pasta com safranina $1 \%$ e montagem em lâminas permanentes, com Entellan.

A descrição microscópica da madeira baseou-se nas recomendações do IAWA Committee (1989). No caso da percentagem dos tecidos, foram realizadas 600 determinações ao acaso, com auxílio de contador de laboratório, conforme proposto por Marchiori (1980). A frequiência de poros foi obtida de forma indireta, a partir de um quadrado de área conhecida, superposto a fotomicrografias de seção transversal da madeira. As medições foram realizadas em microscópio Carl Zeiss, com ocular de escala graduada, no Laboratório de Anatomia da Madeira da Universidade Federal de Santa Maria. Nas características quantitativas, os números entre parênteses correspondem aos valores mínimos e máximos observados; o valor que acompanha a média é o desvio padrão. As fotomicrografias foram tomadas em microscópio Olympus cx40, equipado com câmera digital Olympus Camedia c3000.

\section{DESCRIÇÃO ANATÔMICA}

Madeira de porosidade difusa. Anéis de crescimento distintos, delimitados por fina camada de fibras radialmente estreitas no lenho tardio (Figura 1A,B). 
Vasos: muito numerosos a extremamente numerosos $\left(136 \pm 34(94-212)\right.$ poros $\left./ \mathrm{mm}^{2}\right)$, ocupando $22 \pm 3,9 \%$ do volume da madeira. Conteúdo de coloração escura, ocasionalmente presente. Poros exclusivamente solitários ou solitários, com freqüente contato lateral quando muito numerosos, e de seção oval, circular, até ligeiramente poligonal; muito pequenos ( 37 $\pm 8(19-55) \mu \mathrm{m})$, de paredes espessas $(3,4 \pm$ $0,8(2,5-5) \mu \mathrm{m})$ e sem padrão definido de organização (Figura 1A,B). Elementos vasculares de comprimento médio (505 $\pm 103(290-720)$ $\mu \mathrm{m}$ ), com placas de perfuração simples (Figura 1D), geralmente oblíquas, e com apêndices, geralmente em ambas as extremidades. Pontoações intervasculares pequenas $(4,9 \pm 0,4$ $(4,6-5,1) \mu \mathrm{m})$, alternas e de forma circular, com abertura em fenda inclusa (Figura 1F); ornamentações, ausentes. Pontoações raio-vasculares com aréolas distintas, semelhantes às intervasculares, embora menores $(2,7 \pm 0,4(2,1$ $-3,1) \mu \mathrm{m})$ e geralmente restritas às margens de raios. Espessamentos espiralados, ausentes.

Parênquima axial: representando $14 \pm 3,2 \%$ do volume da madeira e muito distinto das fibras; em faixas com até seis células de largura, no lenho inicial, por vezes mais estreitas e descontínuas ou em curtos segmentos tangenciais uni a bisseriados, além de apotraqueal difuso e difuso-em-agregados, raro paratraqueal escasso (Figura1A,B). Séries parenquimáticas compostas de $6-8(2-16)$ células e $444 \pm 93(245-675) \mu \mathrm{m}$ de altura (Figura 1F,G). Cristais, ausentes a abundantes, em séries de até 11 unidades, dispostos em câmaras ou células distendidas do parênquima axial, maiores do que as adjacentes (Figura 1F). Conteúdo de coloração escura, escasso ou ausente.

Raios: muito numerosos (20 $\pm 2(15-23)$ raios $/ \mathrm{mm}$ ), ocupando $16 \pm 3,1 \%$ do volume da madeira; heterocelulares, reúnem células procumbentes, na parte multisseriada, e 2-5 (1 - 9) fileiras marginais de células eretas, quadradas e, menos frequentemente, procumbentes mais altas do que as do corpo central (Figura 1C,E,F,G). Raios estreitos, com $1-3$ células de largura (Figura 1E,F,G). Raios multisseriados com 6 - 19, mais comumente 8 - 13 células de altura, medindo $208 \pm 67(100-400) \mu \mathrm{m}$; margens mais longas ou de tamanho variável em relação ao corpo central (Figura 1E,F,G). Raios unisseriados com $1-6$ (9) células e $115 \pm 65$ $(20-260) \mu \mathrm{m}$ de altura (Figura 1F,G). Raios axialmente fusionados, frequentes. Células radiais de paredes disjuntas, presentes. Inclusões minerais, células envolventes e células perfuradas, ausentes. Conteúdo de coloração escura, escasso ou ausente.

Fibras: com pontoações distintamente areoladas, visíveis nas faces radiais e tangenciais da parede. Tecido fibroso representando $48 \pm$ $4,3 \%$ do volume da madeira. Fibras de comprimento médio $(1023 \pm 152(790-1370) \mu \mathrm{m})$, com $16 \pm 2(12-21) \mu \mathrm{m}$ de largura, e de paredes finas a espessas e até muito espessas $(5,1 \pm 0,8$ $(3,1-6,8) \mu \mathrm{m})$ (Figura 1A,B). Fibras septadas, fibras gelatinosas e espessamentos espiralados, ausentes. Traqueídeos vasicêntricos, presentes.

Outros caracteres: Variantes cambiais, tubos laticíferos e taniníferos, canais intercelulares, células oleíferas ou mucilaginosas e estratificação, ausentes. Máculas medulares, ocasionais.

\section{ANÁLISE DA ESTRUTURA ANATÔMICA}

A porosidade difusa, os poros muito numerosos e solitários, os elementos vasculares de comprimento médio, as placas de perfuração simples, as pontoações intervasculares alternas, a ausência de espessamentos espiralados, os raios heterogêneos e estreitos, e as fibras de comprimento médio e pontoações areoladas, são aspectos comuns em Mirtáceas (Record \& Hess, 1949; Metcalfe \& Chalk, 1972), bem como na quase totalidade das Mirtoídeas nativas no Estado, com exceção de algumas espécies de Myrceugenia, que tem placas escalariformes, e de Campomanesia, que apresenta raios relativamente largos (Marchiori, 1987, 1988; Santos 

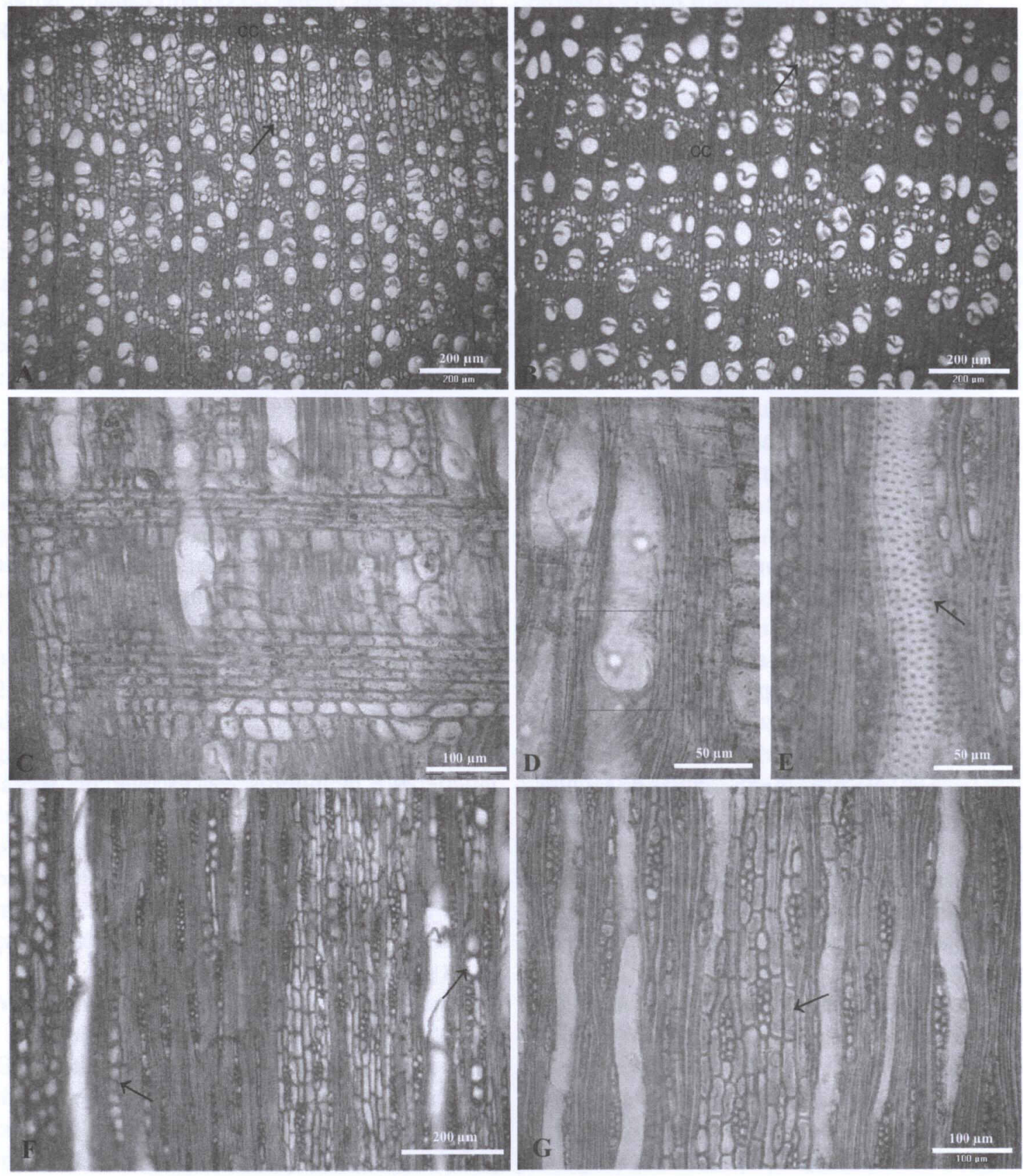

FIGURA 1 - Fotomicrografias da madeira de Myrcianthes pungens. A - Seção transversal, mostrando porosidade difusa, poros solitários, em freqüente contato lateral, parênquima apotraqueal difuso-em-agregados e em faixas largas (seta), e limite de anel de crescimento (cc). B - Mesma seção, com destaque para fibras de paredes muito espessas, poros exclusivamente solitários, de forma oval a circular, e parênquima axial em estreitas faixas descontínuas e curtos segmentos tangenciais (seta). C - Aspecto geral de raios heterogêneos, com células procumbentes, no corpo (seta), e margens de células eretas, quadradas e procumbentes, em seção longitudinal radial. D - Detalhe da mesma seção, mostrando placa de perfuração simples (quadrado). E - Seção longitudinal tangencial, com destaque para pontoações intervasculares alternas (seta). F - Mesma seção, salientando raios estreitos, uni e bisseriados, e séries cristalíferas (seta). G - Séries de parênquima axial (seta) e raios, em seção tangencial. 
\& Marchiori, 2009a,b). Mais frequentes, os espessamentos espiralados são observados em Campomanesia guazumaefolia (Marchiori, 1998), Myrrhinium loranthoides (Marchiori, 1984a), Eugenia involucrata (Marchiori, 1984b) e em diversas espécies de Myrceugenia (Marchiori, 1987; 1988).

Sob o ponto de vista taxonômico, destaca-se a ausência de ornamentações no pontoado intervascular e, sobretudo, o parênquima axial em faixas tangenciais. De todas as espécies sulrio-grandenses, até o momento descritas, apenas Eugenia uniflora mostra padrão semelhante ao presentemente descrito. Myrcianthes pungens, aliás, é de mais difícil separação de Eugenia uniflora do que de Myrcianthes cisplatensis, que apresenta parênquima apotraqueal difuso-em-agregados. Este fato depõe favoravelmente à conhecida homogeneidade estrutural da família (pelo menos da tribo Myrteae ou subfamília Myrtoideae), pois, não raro, observa-se variabilidade menor entre gêneros do que em espécies de um mesmo gênero, à exemplo do observado na morfologia externa.

A ausência de ornamentações no pontoado intervascular, aspecto pouco frequente em Myrtaceae, segundo a literatura, foi também registrada para outras espécies nativas como Eugenia uniflora (Santos \& Marchiori, 2009d) e Eugenia mansoi (Santos \& Marchiori, 2009c). O uso deste caráter para fins taxonômicos, no entanto, é dificultado em espécies com pontoações pequenas e poros solitários, caso predominante na família; entre outras publicações, não constam referências sobre o pontoado intervascular em Marchiori (1984a,b), Marchiori \& Brum (1997), Barros et al. (2001; 2003), Denardi \& Marchiori (2005) e Marchiori et al. (2008).

Com relação ao descrito por Richter \& Dallwitz (2009), as diferenças mais importantes residem em caracteres quantitativos, sobretudo na altura de raios e séries de parênquima axial, que são maiores (500 - $1000 \mu \mathrm{m}$, os mais altos) e menores ( 3 - 5 células), respectivamente, do observado.

No presente estudo foram observados cristais em apenas uma das amostras, neste caso com abundância. Richter \& Dallwitz (2009), por sua vez, não mencionam o caráter no material por eles investigado. Cabe salientar que esta divergência não contraria as possibilidades referidas pelo IAWA Committee (1989) para a madeira das Dicotiledôneas. A ocorrência de cristais mostra-se de valor taxonômico, especialmente quando muito abundantes (Appezzato-da-Gloria \& Carmello-Guerreiro, 2003; Rodrigues, 2005). Entre os autores que valeram-se do referido caráter para a separação das espécies, incluem-se Richter (1982, apud Rodrigues, 2005) e Soffiatti \& Angyalossy-Alfonso (1999). Para a espécie em estudo, no entanto, devido à presença ocasional, os cristais carecem de valor diagnóstico.

\section{REFERÊNCIAS BIBLIOGRÁFICAS}

APPEZZATO-DA-GLÓRIA, B.; CARMELLOGUERREIRO, S.M. Anatomia Vegetal. Viçosa: UFV, 2003. 438 p.

BARROS, C.F.; CALLADO, C.H.; MARCON, M.L.; COSTA, C.G.; CUNHA, M.; LIMA, H.R.P.; MARQUETE, O. Madeiras da Mata Atlântica: anatomia do lenho de espécies ocorrentes nos remanescentes florestais do estado do Rio de Janeiro, Brasil. Rio de Janeiro: Instituto de Pesquisas Jardim Botânico do Rio de Janeiro, 2001. $94 \mathrm{p}$.

BARROS, C.F.; CALLADO, C.H.; CUNHA, M.; MARCON, M.L.F.; TAMAIO, N.; MARQUETE, O.; COSTA, C.G. Madeiras da Mata Atlântica: anatomia do lenho de espécies ocorrentes nos remanescentes florestais do estado do Rio de Janeiro, Brasil. Rio de Janeiro: Instituto de Pesquisas Jardim Botânico do Rio de Janeiro. 2003. 86 p.

BURGER, L.M.; RICHTER, H.G. Anatomia da Madeira. São Paulo: Ed. Nobel, 1991. 154 p.

DENARDI, L.; MARCHIORI, J.N.C. Anatomia do lenho da murta, Blepharocalyx salicifolius 
(H.B.K.) Berg. Ciência Florestal, Santa Maria, v. 15 , n. 3 , p. $267-274,2005$.

DUJARDIN, E. P. Eine neue HolzZellulosenfaerbung. Mikrokosmos, n. 53, p. 94, 1964.

IAWA COMMITTEE. IAWA list of microscopic features for hardwood identification. IAWA Bulletin, v.10, n. 3, p. 218-359, 1989.

LORENZI, H. Árvores brasileiras: manual de identificação e cultivo de plantas arbóreas nativas do Brasil. Nova Odessa: Editora Plantarum, $1992.352 \mathrm{p}$.

MARCHIORI, J.N.C. Estudo anatômico do xilema secundário de algumas espécies dos gêneros Acacia e Mimosa, nativas no Estado do Rio Grande do Sul. 1980. 186f. Dissertação (Mestrado em Engenharia Florestal) - Universidade Federal do Paraná, Curitiba, 1980.

MARCHIORI, J.N.C. Anatomia descritiva da madeira do murtilho Myrrhinium loranthoides (Hook. et Arn.) Burret (Myrtaceae). Revista do Centro de Ciências Rurais, Santa Maria, v. 14, n. 1, p. 43-50, 1984a.

MARCHIORI, J.N.C. Anatomia da madeira de Eugenia involucrata DC. (Myrtaceae). Ciência e Natura, Santa Maria, v. 6, p. 127-136, 1984b.

MARCHIORI, J.N.C. Anatomia descritiva da madeira de Myrceugenia myrtoides Berg. Ciência e Natura, Santa Maria, v. 9, p. 113-120, 1987.

MARCHIORI, J.N.C. Estudo anatômico da madeira de Myrceugenia glaucescens (Camb.) Legr. et Kaus. Ciência e Natura, Santa Maria, v. 10, p. 105-113, 1988.

MARCHIORI, J.N.C, BRUM, E.T. Anatomia da madeira do guamirim-facho, Calyptranthes concinna DC. (Myrtaceae). Ciência Rural, Santa Maria, v. 27, n. 2, p. 217-222, 1997.

MARCHIORI, J.N.C. Estudo anatômico da madeira de sete-capotes, Campomanesia guazumaefolia (Camb.) Berg (Myrtaceae). Ciência Rural, Santa Maria, v. 28, n. 1, p. 47-51, 1998.

MARCHIORI, J.N.C.; DENARDI, L.; FERREIRA, M.R. Anatomia da madeira de Myrcianthes gigantea (Legr.) Legr. Balduinia, Santa Maria, n. 12, p. 27-31, 2008.
METCALFE, C.R.; CHALK, L. Anatomy of the Dicotyledons. Oxford: Clarendon Press, 1972. $1500 \mathrm{p}$.

RECORD, S.J.; HESS R.W. Timbers of the New World. New Haven: Yale University Press, 1949. $640 \mathrm{p}$.

RICHTER, H.G.; DALLWITZ, M.J. Commercial timbers: descriptions, illustrations, identification, and information retrieval. 2000 onwards. Version: 25th June 2009. Disponível em: <http:/ / delta-intkey.com/wood/pt/ww w/ myrmypun.htm>. Acesso em 3 nov. 2009.

RODRIGUES, T.T. Os efeitos do solo contaminado com petróleo na estrutura anatômica e estado nutricional do lenho jovem de Campomanesia xanthocarpa Berg (Myrtaceae) e Sebastiania commersoniana (Baillon) Smith \& Downs (Euphorbiaceae). Tese (Doutorado) - Universidade Federal do Paraná, Curitiba, 2005.

SANTOS, S.R.; MARCHIORI, J.N.C. Anatomia do xilema secundário de Myrceugenia euosma (O) Berg) D. Legrand (Myrtaceae). Balduinia, n. 16, p. 24-29, 2009a.

SANTOS, S.R.; MARCHIORI, J.N.C. Caracterização microscópica do lenho de Campomanesia xanthocarpa O. Berg O. Berg (Myrtaceae). Balduinia, n. 18, p. 10-14, 2009b.

SANTOS, S.R.; MARCHIORI, J.N.C. Anatomia do xilema secundário de Eugenia mansoi O. Berg (Myrtaceae). Balduinia, n. 16, p. 6-12, 2009c.

SANTOS, S.R.; MARCHIORI, J.N.C. Anatomia da madeira de Eugenia uniflora L. (Myrtaceae). Balduinia, n. 17, p. 11-16, 2009d.

SILVA, P.F.. Características físico-mecânicas das espécies lenhosas do sul do Brasil. Porto Alegre: Instituto de Pesquisas Tecnológicas do Rio Grande do Sul, 1967. (Bol. n. 42).

SOBRAL, M. A família Myrtaceae no Rio Grande do Sul. São Leopoldo: Unisinos, 2003. 215 p.

SOFFIATTI, P.; ANGYALOSSY-ALFONSO, V. Estudo anatômico comparativo do lenho e da casca de duas espécies de Eugenia L. (Myrtaceae). Revista Brasileira de Botânica, São Paulo, v. 22, n. 2, p. 175-184, 1999. 